\title{
Effect of Telestroke Practices on Short-Term Mortality in Ischemic Stroke Patients
}

\section{Telestroke Uygulamalarının İskemik İnme Hastalarında Kısa Süreli Mortalite Üzerine Etkisi}

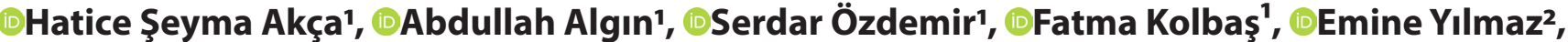

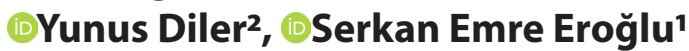

\author{
'University of HealthSciences, Ümraniye Education and Research Hospital, Department of Emergency Medicine, Istanbul, Turkey \\ ${ }^{2}$ University of Health Sciences, Ümraniye Education and Research Hospital, Department of Neurology, Istanbul, Turkey
}

\begin{abstract}
Aim: It was aimed to compare the year we started using telestroke application in ischemic stroke patients with the previous year in which we did not use telestroke application in terms of patient prognosis.
\end{abstract}

Material and Method: Stroke patients presenting for whom WhatsApp was used for telestroke purposes, were evaluated as the telestroke group. The previous year it was a pre-telestroke group. In this prospectively planned study, the pre-telestroke and telestroke groups were compared in terms of age, gender, chronic disease characteristics, onset of symptoms, aspirin, warfarinuse, door-to$\mathrm{CT}$, door-to-consultation and door-to-treatment times, prognosis, and 30-day mortality.

Results: A total of 727 patients clinically and radiologically confirmed to have ischemic stroke were included in the study. There were $252(34.6 \%)$ patients in the pre-telestroke group and $475(65,4 \%)$ patients in the telestroke group. Both rtPA and thrombectomy treatment were significantly higher in the telestroke group $(p<0.001)$. In the first 24 -hour evaluation, the rate of discharge increased and hospital admission and mortality decreased in the telestroke group $(p<0.001)$. There was no statistically significant difference between the groups in terms of poor prognosis and 30 -day mortality $(p=0.470$ and $p=0.625$, respectively).

Conclusion: Telestroke practices not only provide access to there levant clinical branch for early consultation but also facilitate time lytreatment thus leading to improvement in prognosis.

Keywords: Telestroke, ischemicstroke, rtPA, thrombectomy, WhatsApp application
Öz

Amaç: Bu çalışmada, telestroke uygulamalarının, bu uygulamanın kullanıldığı bir dönem öncesi ve kullanım sırasında başvuran hastaların verilerini karşılaştırarak hasta prognozu ve mortalite üzerindeki etkisini değerlendirmeyi amaçladık.

Gereç ve Yöntem: WhatsApp uygulaması kullanılmayan dönem pretelestroke olarak adlandırıldı ve WhatsApp uygulaması kullanılan grup telestroke grubu olarak adlandırıldı. Prospektif olarak planlanan bu çalışmada, telestroke öncesi ve telestroke grupları yaş, cinsiyet, kronik hastalık özellikleri, semptomların başlangıcı, aspirin, varfarin kullanımı, kapı-CT, kapı-konsültasyon ve kapı-tedavi süreleri, prognoz ve 30 günlük mortalite açısından karşılaştırıldı.

Bulgular: Klinik ve radyolojik olarak doğrulanan 727 iskemik stroke hastası çalışmaya dahil edildi. Pre-telestroke grubuna ait hasta sayısı 252 (34,6\%) olup, telestroke grubuna ait hasta sayısı ise $475(65,4 \%)$ idi. Telestroke uygulaması kullanılan grupta, kullanılmayan gruba göre hem r-tPA hem de trombektomi tedavisi anlamlı olarak daha yüksek oranda idi $(p<0,001)$. Illk 24 saatlik değerlendirmede telestroke grubunda taburculuk oranı artmış ve hastane servis yatışı ve mortalite azalmıştır ( $p<0,001)$. Kötü prognoz ve 30 günlük mortalite açısından gruplar arasında istatistiksel olarak anlamlı fark yoktu (sırasıyla $p=0.470$; $\mathrm{p}=0,625)$.

Sonuç: Tele-stroke uygulamaları, erken konsültasyonla ilgili branşa veya görüntüleme sistemlerine ulaşımı sağlamakla kalmaz; çoğunlukla tedavinin zamanında ve efektif yapılmasına, erken taburculuğa dolayısı ile de prognozda iyileşmeye neden olur.

Anahtar kelimeler: Telestroke, iskemikstroke, r-tPA, trombektomi, WhatsApp uygulaması

Corresponding (iletişim): Hatice Şeyma Akça, University of Health Sciences, Ümraniye Education and Research Hospital, Department of Emergency Medicine, Istanbul, post code: 34764 , Turkey

E-mail (E-posta): drhaticeseyma_@hotmail.com

Received (Geliş Tarihi): 21.07.2021Ａccepted (Kabul Tarihi): 04.12.2021 


\section{INTRODUCTION}

Stroke is a clinical condition that occurs due to the sudden onset of focal or general neurological dysfunction accompanied by circulatory disturbance lasting more than 24 hours. ${ }^{[1]}$ After the stroke diagnosis is made using anamnesis, physical examination, and advanced imaging, the primary goal in the treatment process is an antiischemic protocol after providing vital functions via airway, respiration, and circulation routes.

As the main thrombolytic agent of anti-ischemic therapy, tissue plasminogen activator (rtPA) acts by inhibiting the conversion of plasminogen to plasmin. The rtPA should be given within the first 4.5 hours, which is the effective time from the onset of stroke. ${ }^{[2,3]}$ Thrombectomy is the main treatment option within the first 24 hours in patients that do not present to hospital during the first 4.5 hours or in those with contraindications to rtPA. ${ }^{[4]}$

The early application of rtPA treatment is necessary in terms of effectiveness, and telestroke practices have been introduced to both prevent delaying treatment due to environmental and/or social reasons and to shorten the door-needle time(DTN) which is considered important in terms of not delaying targeted treatment due to patient transport. ${ }^{[2,5]}$ For this purpose, the WhatsApp application is being used in developing countries or those that cannot access developed communication tools due to economic reasons. Telestroke is considered an ideal system for sharing data, pictures, and videos, and provides easy access in a short amount of time. ${ }^{[6,7]}$

\section{Aim}

This study aimed to evaluate the effect of telestroke practices on patient prognosis and mortality by comparing the data of patients that presented before and during a period when this application was in use.

\section{MATERIAL AND METHOD}

\section{Study design}

This comprehensive observational study was conducted in the Emergency Medicine Clinic of Ümraniye Education and Research Hospital, which accepts an average of 438,000 patients per year. An emergency medicine specialist evaluates the patients presenting to our hospital with stroke symptoms, and those that are considered to have a clinical stroke are transferred to the radiology unit for imaging. During this transfer, the emergency medicine specialist shares the demographic data, clinical state, and symptom onset time in a WhatsApp group, in which the stroke team members of the hospital-emergency medicine specialists, neuroradiologists, and neurologists-are registered. The stroke team evaluates the patient's radiological images through the PACS system. After radiological imaging, patients for whom the stroke team has made rtPA treatment decisions are hospitalized in the stoke intensive care unit (ICU) or other departments, and thrombolytic therapy is started. Patients planning to undergo a thrombectomy are transferred to the thrombectomy center located $12 \mathrm{~km}$ from the hospital and admitted back to the stroke ICU of our hospital after this procedure.

In our hospital, the telestroke protocol was implemented on October 1, 2018. In this study, using the hospital computerbased data system, patients with an ischemic stroke admitted between October 1, 2017, and October 1, 2018, were retrospectively evaluated as the pre-telestroke group. After the implementation of the telestroke protocol, patients presenting with an ischemic stroke between October 1, 2018, and October 1, 2019, were prospectively followed-up on by the researchers and evaluated as the telestroke group. The data of these two groups were compared in terms of short-term mortality and outcome.

\section{Study Population and Data Collection}

All patients presenting to our clinic with a manifestation of stroke were evaluated. Of the patients with a pre-diagnosis of ischemic stroke, those diagnosed via brain CT with a hemorrhagic stroke or other central pathologies (masses and spontaneous subarachnoid hemorrhage), those with metabolic diseases (diabetic ketoacidosis, hyperosmolar nonketotic coma, hypernatremia, etc.), and trauma patients were excluded. Patients who were referred to the ICUs of other hospitals due to bed occupancy were also excluded from the study since their mortality and outcome information could not be obtained. Finally, the study included patients over the age of 18 years that were diagnosed with ischemic stroke based on CT, CT-angiography, and MR diffusion where necessary, after receiving their consent or that of their firstdegree relatives.

This prospectively planned study compared the pretelestroke and telestroke groups in terms of age, gender, chronic disease characteristics, onset of symptoms, aspirin use, warfarin use, door-to-CT, door-to-consultation and door-to-treatment times, prognosis, and 30-day mortality. In relation to prognosis, the patients with good/poor clinical outcome were identified and those discharged after admission to the emergency department (ED) or another hospital service were considered to have a 'good clinical outcome,' while the cases that still required intensive care at the time the study was terminated were evaluated as having a 'poor clinical outcome.'

The primary outcome was 30-day all-cause mortality after ED admission. The secondary outcomes were hospitalization or admission to ICU from ED, discharge from ED, and mortality in ED.

\section{Statistical Analysis}

All statistical analyses were performed using SPSS version 16.0 for Windows (SPSS Inc, Chicago, IL, USA). The normality analysis of continuous data was undertaken 
using the Kolmogorov-Smirnov test. Categorical data were presented as $\mathrm{n}(\%)$ and compared using the chi-squared test. Quantitative variables were presented as median and interquartile range (IQR, 25th- $75^{\text {th }}$ percentile) and compared between the two groups using the Mann-Whitney test and Student's t-test according to the normality of data distribution. A p-value of less than 0.05 was considered statistically significant.

\section{Ethics}

For the study, ethical approval was obtained from the local clinical research ethics committee of our hospital (date: March 18, 2020, number: B.10.1.TKH.4.34.H.GP.0.01/62). Patients with a sufficient level of consciousness, or the relatives of patients who did not have sufficient consciousness, were invited to participate in the study. The patients or their relatives who decided to participate in the study signed an informed consent form.

\section{RESULTS}

Of the 871 patients that presented to our clinic with a stroke, 144 were excluded due to cranial or metabolic pathologies other than ischemia, incomplete data, or lack of consent. A total of 727 ischemic stroke patients with clinical and radiological confirmation were included in the study (Figure 1).

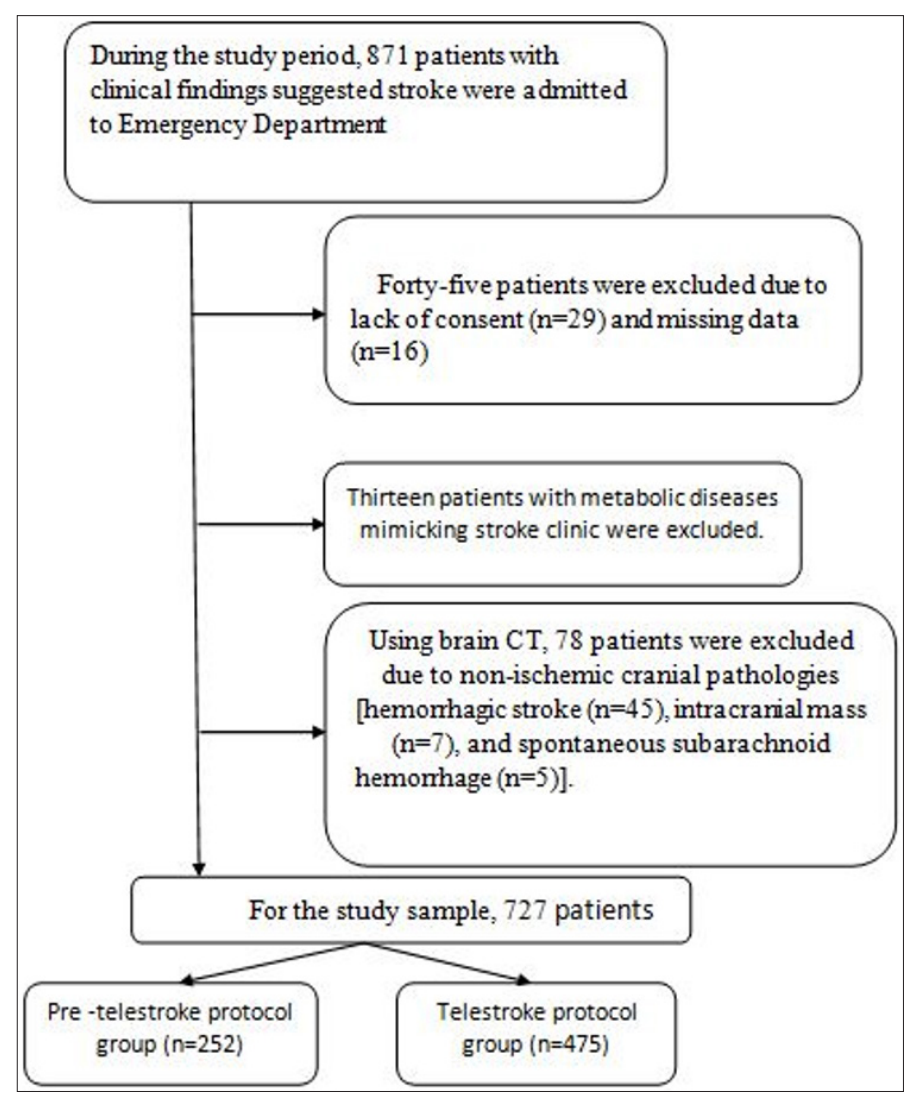

Figure 1. Numerical distribution of the patients included in and excluded from the study
The mean age of the patients was $66 \pm 12.51$ years, and 377 $(51.8 \%)$ were male. While $599(82.4 \%)$ of the patients had a good clinical outcome, $128(17.6 \%)$ had a poor clinical outcome. A CT scan was performed in $98.9 \%$ of the patients and diffusion MRI in $86.9 \%$. In $66.9 \%$ of the patients, a CT angiography was undertaken to evaluate vascular occlusion.

Table 1 displays the basic characteristics, comorbidities, medication, and clinical characteristics of the patients belonging to both groups, as well as the time to access treatment, prognosis, and mortality. There were $252(34.6 \%)$ patients in the pretelestroke group and $475(65.4 \%)$ in the telestroke group. While $37.3 \%$ of the patients in the pre-telestroke group presented within the first 4.5 hours of their onset of symptoms, $64.4 \%$ in the telestroke group visited the hospital within the first 4.5 hours. Meanwhile, $15.4 \%$ of the patients in the telestroke group were discharged within 24 hours. The discharge rate in the pretelestroke group was $1.2 \%(p<0.001)$ The median door-to-CT time was similar in both groups with no statistically significant difference [15 (10) and 15 (8), respectively, $\mathrm{p}=0.409]$. The mean door-to-rtPA times of the patients in both groups were similar, and there was no significant difference between them in terms of the time to access treatment $(95.83 \pm 46.52$ and $88.75 \pm 32.43$, respectively, $\mathrm{p}=0.627$ ). The mean door-to-thrombectomy time was $107.86 \pm 9.94$ minutes in the pre-telestroke group and $145.83 \pm 50.5$ minutes in the telestroke group $(p<0.001)$.

Table 2 portrays the relationship between the prognosis and mortality of the patients who received rtPA or thrombectomy treatment. Door-to-consultation time in patients who received rtPA was 20 (10-97), and $36(10-1647)(p<0.001)$ in patients who did not receive rtPA. Door-to-consultation time in patients who received a thrombectomy was 26 (10-180), and 35 (10-1647) $(p=0.002)$ in patients who did not receive thrombectomy. There was a statistically significant difference in the doorto-consultation time between the patients that received initial treatment and those that did not (rtPA/thrombectomy) $(\mathrm{p}<0.001)$.

We evaluated the prognosis and mortality of the telestroke group according to treatment modality in Table 3. While $72.6 \%$ of patients who received thrombectomy treatment had a poor prognosis, the rate of poor prognosis was $85.4 \%$ in patients who did not receive thrombectomy treatment $(p=0.004)$. Conversely, mortality was $20.2 \%$ in patients who received thrombectomy treatment, and $8.4 \%$ in patients who did not $(p=0.001)$. While there was no statistically significant difference in clinical outcome or mortality between the rtPA and non-rtPA groups, there was a statistically significant difference in these parameters when comparing the patients that underwent thrombectomy as their initial treatment to the non-thrombectomy group $(p=0.004)$. The telestroke group was separately evaluated to determine whether there was a difference in terms of the treatment protocol, and the same results were obtained with the difference table in terms of the treatment protocol of the whole sample; thus, the use of WhatsApp for telestroke was not found superior in relation to the implemented treatment protocol (Table 3). 


\begin{tabular}{|c|c|c|c|c|c|c|c|}
\hline & Total & Pre-telestroke & Telestroke & p value & survivor & mortality & p value \\
\hline Age/years & $66 \pm 12.51$ & $68.92 \pm 14.18$ & $69.70 \pm 14.34$ & 0.485 & $68.93 \pm 14.32$ & $73.52 \pm 13.33$ & 0.007 \\
\hline Gender & & & & 0.466 & & & 0.639 \\
\hline Male & $377(51.8 \%)$ & $126(50 \%)$ & $251(52.8 \%)$ & & $338(89.7)$ & 39 (10.3\%) & \\
\hline \multicolumn{8}{|l|}{ Comorbidities } \\
\hline$C A D$ & $233(32 \%)$ & $48(19 \%)$ & $185(38.9 \%)$ & $<0.001$ & $214(91.8 \%)$ & $19(8.2 \%)$ & 0.107 \\
\hline CKD & $42(5.7 \%)$ & $17(6.7 \%)$ & $25(5.3 \%)$ & 0.415 & $38(90.5 \%)$ & $4(9.5 \%)$ & 0.773 \\
\hline CVD & $174(23.9 \%)$ & $51(20.2 \%)$ & $123(25.9 \%)$ & 0.089 & 155 (89.1\%) & 19 (10.9\%) & 0.979 \\
\hline \multicolumn{8}{|l|}{ Drug use history } \\
\hline Aspirin & $235(32.3 \%)$ & $71(28.2 \%)$ & $164(34.5 \%)$ & 0.082 & 219 (93.2\%) & $16(6.8 \%)$ & 0.015 \\
\hline Unknown & 107 (14.72\%) & $4(1.6 \%)$ & $103(21.7 \%)$ & & $93(86.9 \%)$ & $14(13.1 \%)$ & \\
\hline Door-to-CT time(min) & $14(10)$ & $15(10)$ & $15(8)$ & 0.409 & $15(8)$ & $15(9)$ & 0.368 \\
\hline Door-to-consultation time (min) & $55(79)$ & $97.5(79)$ & $34(55)$ & $<0.001$ & $55(77)$ & $56(94)$ & 0.846 \\
\hline Door-to-r-tPA time (min) & $90.70 \pm 36.73$ & $95.83 \pm 46.52$ & $88.75 \pm 32.43$ & 0.627 & $89.79 \pm 34.8$ & $85.20 \pm 11.6$ & 0.520 \\
\hline Door-to-thrombectomy time (min) & $149.15 \pm 69.65$ & $107.86 \pm 9.94$ & $145.83 \pm 50.53$ & $<0.001$ & $139.23 \pm 50.34$ & $157.89 \pm 45.16$ & 0.144 \\
\hline First 24-hour evaluation & & & & $<0.001$ & & & $<0.001$ \\
\hline Discharged & $76(10.5 \%)$ & $3(1.2 \%)$ & $73(15.4 \%)$ & & $76(100 \%)$ & & \\
\hline Admitted to hospital services & $549(75.5 \%)$ & $218(86.5)$ & $331(69.7)$ & & $523(67.1 \%)$ & $26(32.9 \%)$ & \\
\hline Admitted to ICU & $100(13.8 \%)$ & $30(11.9 \%)$ & 70 (14.7\%) & & 49 (33.7\%) & $51(66.4 \%)$ & \\
\hline Died & $2(0.2)$ & $1(0.4 \%)$ & $1(0.2 \%)$ & & & $2(2.5 \%)$ & \\
\hline \multicolumn{8}{|l|}{ Treatment } \\
\hline
\end{tabular}

(DM: Diabetes mellitus, HT: hypertension, CAD: coronary artery disease, CKD: chronic kidney disease, CVD: cerebrovascular disease)

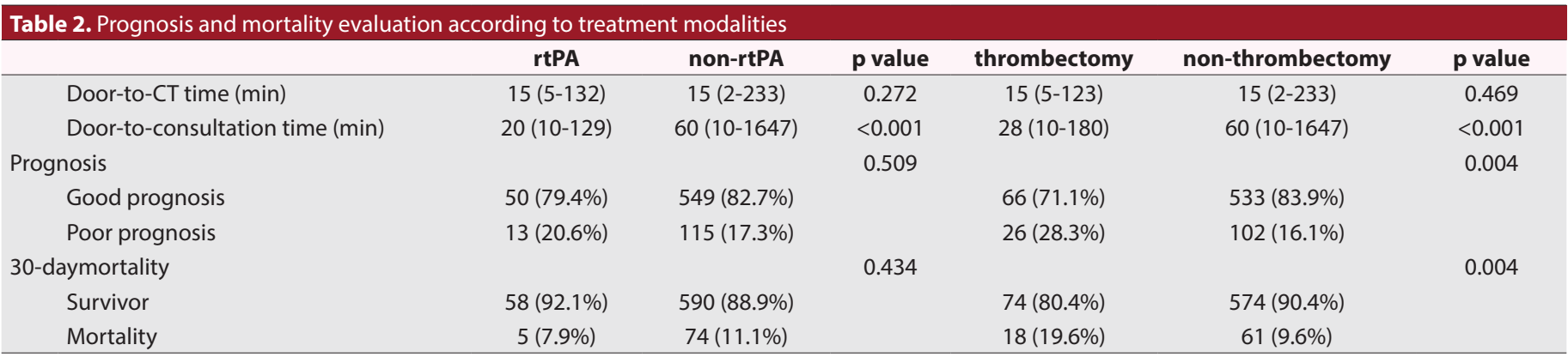

\begin{tabular}{|c|c|c|c|c|c|c|}
\hline & tPA & non-tPA & $p$ value & thrombectomy & non-thrombectomy & p value \\
\hline Door-to-CT time (min) & $15(5-75)$ & $15(5-134)$ & 0.428 & $15(5-123)$ & $15(5-134)$ & 0.542 \\
\hline Door-to-consultation time (min) & $20(10-97)$ & $36(10-1647)$ & $<0.001$ & $26(10-180)$ & $35(10-1647)$ & 0.002 \\
\hline Good prognosis & $50(87.7 \%)$ & $345(82.5 \%)$ & & $23(27.4 \%)$ & $57(14.6 \%)$ & \\
\hline Poor prognosis & $7(12.3 \%)$ & $73(17.5 \%)$ & & $61(72.6 \%)$ & $334(85.4 \%)$ & \\
\hline Mortality & $4(7 \%)$ & $46(11 \%)$ & & $17(20.2 \%)$ & $33(8.4 \%)$ & \\
\hline
\end{tabular}


Table 4. Evaluation of time parameters and treatment modalities according to mortality and prognosis in the pre-telestroke and telestroke groups

\begin{tabular}{|c|c|c|c|c|c|c|}
\hline \multirow[b]{2}{*}{ mortality } & \multicolumn{6}{|c|}{ prognosis } \\
\hline & $\begin{array}{c}\text { pre-telestrokegroup } \\
(n=29,11.5 \%)\end{array}$ & $\begin{array}{l}\text { telestroke group } \\
(\mathrm{n}=50,10.5 \%)\end{array}$ & p value & $\begin{array}{l}\text { pre-telestroke } \\
\text { group }(n=48)\end{array}$ & $\begin{array}{c}\text { telestroke group } \\
(n=80)\end{array}$ & p value \\
\hline Door-to-CT time (min) & $14(10-132)$ & $17(10-123)$ & 0.141 & $13.5(5-233)$ & $17(10-123)$ & 0.138 \\
\hline Door-to-consultation time (min) & $115(15-300)$ & $23(11-180)$ & $<0.001$ & $108.5(15-300)$ & $32.5(11-180)$ & $<0.001$ \\
\hline tPAapplied first treatment & 1 & 4 & 0.647 & 6 & 7 & 0.552 \\
\hline Thrombectomy applied as first treatment & 1 & 17 & 0.002 & 3 & 23 & 0.002 \\
\hline Door-to-rtPA time (min) & 100 & $81.5 \pm 9.47$ & 0.179 & $95.83 \pm 46.52$ & $93.71 \pm 36.11$ & 0.928 \\
\hline Door-to-thrombectomy time (min) & 120 & $160 \pm 45.5$ & 0.404 & $110 \pm 14.14$ & $164.17 \pm 44.52$ & 0.105 \\
\hline
\end{tabular}

When consultation, imaging, and treatments used were compared in relation to mortality using the Spearman correlation analysis, there was no correlation between the door-to-consultation time and mortality ( $r=0.007, p=0.846)$. Similarly, mortality had no correlation with the door-to$\mathrm{CT}$, door-to-rtPA, and door-to-thrombectomy times ( $r=-$ 0.033, $\mathrm{p}=0.368 ; \mathrm{r}=-0.006, \mathrm{p}=0.960 ;$ and $\mathrm{r}=-0.165, \mathrm{p}=0.112$, respectively).

Table 4 presents the results of the examining the time-related parameters between the pre-telestroke and telestroke groups undertaken by isolating the patients with a mortality course and poor clinical outcome. In the mortal group's door-toconsultation time was 115 (15-300) in pre-telestroke groups and 23 (11-180) in telestroke groups $(p=0.141)$. In the poor clinical outcome groups, the door-to-consultation time was 108.5 (15-300) in pre-telestroke groups and 32.5 (11-180) in telestroke groups $(p<0.001)$. There was a statistically significant difference in the door-to-consultation time in patients with mortality and poor clinical outcomes when compared to the other outcome group $(p<0.001)$, despite the absence of clinical significance and similar death rates. The door-to-consultation time was shorter in the telestroke group. The door-to-CT time (min), rtPA applied as first treatment, thrombectomy applied as first treatment, door-to-rtPA time, and door-to-thrombectomy time data did not create a statistically significant difference in the pre-telestroke and telestroke groups, both in the mortality group and in the group with a poor prognosis (Table 4).

Telestroke did not have any superiority considering the effects of rtPA and thrombectomy treatment protocols, door-to-rtPA time, and door-to-thrombectomy time on mortality and prognosis.

\section{DISCUSSION}

WhatsApp can be used in clinical practices in managing emergency cases as an inexpensive and easily accessible method to achieve fast decisions on treatment protocols. This study aimed to compare the period in which the telestroke WhatsApp group was used and the period when it was not used to investigate its effect on patient prognosis and mortality. When comparing the pre-telestroke and telestroke groups, there was no statistical difference in terms of poor clinical outcome and mortality rates; however, a statistically significant difference was observed in relation to the rates of discharge and hospitalized treatment. The rate of discharge from the hospital within the first 24 hours of presentation was significantly higher and the rate of receiving hospitalized treatment was significantly lower in the telestroke group.

In the literature, WhatsApp is found to be used as an in-hospital communication tool for consultation, sharing radiological images, and tele-neurological purposes. ${ }^{[8]}$ In Northern Ireland, the first use of this application for tele-neurological purposes was described in 2003, and entered into routine use in certain centers in 2016.9 ${ }^{[9]}$ In a study in which neuroradiological images were shared by e-mail, Saadi et al. reported reduced cost and increased efficiency. ${ }^{[6]}$ Médecins Sans Frontières, an international humanitarian medical non-governmental organization, provided access to its web-based messaging system to facilitate the access of doctors to all consultants. ${ }^{[10]}$

In a study comparing the consultation times of patients with intracerebral hemorrhage according to whether they underwent the normal procedure or a telemedicine protocol, Ford et al. found that blood pressure and anticoagulant reversibility were taken under control in a shorter time in the telemedicine group, to an extent that it significantly affected patient outcome. ${ }^{[1]}$ Similarly, in our study, the door-toconsultation time was significantly shorter in the telestroke group. Reducing the door-to-consultation time (min) seems to be very important in terms of both alerting the hospital system and making treatment decisions quickly in order to provide neuroplasticity, which refers to regaining neurological functions of the brain.

In a meta-analysis undertaken by Baratloo et al., the time from the onset of the event to arriving at the emergency door was lower in the telestroke group than the control group. ${ }^{[12]}$ In a 10-year telestroke study that used teleconsultation and video conferencing, Barna et al. reported that the time from the onset of the event to the emergency door decreased in the telestroke group. ${ }^{[13]}$ However, Mazighi et al. found no significant difference in the time from the onset of the event to arrival at the emergency door according to whether telestroke was used. ${ }^{[14]}$ Similarly, in our study, the rate of patients presenting within the first 4.5 hours of the onset of their symptoms was significantly higher and their onset of event to the emergency door time was significantly lower in the telestroke group.

Lee et al., conducting a study with 259 patients over two periods of time-before and after the introduction of the telestroke system into their hospital-found that the time from the beginning of telestroke consultation to rtPA application 
(door-to-rtPA/min) decreased. ${ }^{[15]}$ Fonarow et al. and a metaanalysis by Baratloo et al. also reported that the door-to-rtPA/ min time was significantly decreased in the telestroke group. $[2,12]$ In another study in which 959 stroke patients-of whom 523 were teleneurology patients-were retrospectively examined, the door-to-rtPA time was significantly shorter in the telestroke group, but there was no statistically significant difference between the groups in terms of the door-tothrombectomy time. ${ }^{[16]}$ In another study, the effectiveness of the pre-hospital telestroke system was investigated with 650 patients that were transferred to the hospital without telestroke and 289 transferred to the hospital using telestroke, and no statistically significant difference was found between the two groups in relation to thrombolytic treatment. ${ }^{[17]}$ In our study, we observed that the door-to-thrombectomy/min time was longer in the telestroke group compared to the pre-telestroke group $(p<0.001)$, and the door-to-rtPA time was 7 lower in the telestroke group, but without statistical significance $(p=0.627)$.

Gutowitz et al. compared teleneurology and non-teleneurology groups in terms of rtPA and thrombectomy treatments and determined no significant difference. ${ }^{[16]}$ In a multicenter, cross-sectional study, including 29 hospitals, that examined a two-year telestroke period, the rate of rtPA treatment was higher in the hospital where telestroke was used than in other hospitals. ${ }^{[18]}$ The results of our study revealed that the rates of both rtPA and thrombectomy treatments were significantly higher in the group in which the telestroke system was used compared to the pre-telestroke group $(p<0.001)$.

In telestroke studies, the rate of hospital discharge was higher and the in-hospital mortality rate was lower in the telestroke group compared to the pre-telestroke group. ${ }^{[2,12-14]}$ In a study conducted by Sanchez et al., who examined the relationship between mortality and use of telestroke, the authors did not find a statistically significant difference between the hospitals that did and did not use this system. ${ }^{[18]}$ In the current study, although no statistically significant difference was detected in terms of poor prognosis and 30-day mortality in the comparison of the pre-telestroke and telestroke discharge within the first 24 hours however a significant decrease in the hospitalization rate in the telestroke group. We consider that this is due to the decrease in door-to-consultation/min and door-to-CT/min in the telestroke group.

\section{Limitations}

We consider that the reason the number of patients in the pre-telestroke group was approximately twice the number of those in the telestroke group was that our hospital has been promoted as a stroke hospital since the day it started to apply the telestroke protocol. Conducting further studies in more similar groups will provide clearer results on mortality and outcome. Furthermore, since a number of our patients were still hospitalized in the ICU at the time of data analysis, we were not able to evaluate the final clinical outcome in all patients; thus, we had to add these patients to the poor clinical outcome group which also included the mortality cases.

\section{CONCLUSION}

Telestroke practices not only provide access to the relevant clinical branch for early consultation or imaging studies, but also facilitate timely and effective treatment as well as early discharge, thus leading to improvement in prognosis.

\section{ETHICAL DECLARATIONS}

Ethics Committee Approval: For the study, ethical approval was obtained from the local clinical research ethics committee of our hospital (date: March 18, 2020, number: B.10.1.TKH.4.34.H.GP.0.01/62).

Informed Consent: Because the study was designed retrospectively, no written informed consent form was obtained from patients.

Referee Evaluation Process: Externally peer-reviewed.

Conflict of Interest Statement: The authors have no conflicts of interest to declare.

Financial Disclosure: The authors declared that this study has received no financial support.

Author Contributions: All of the authors declare that they have all participated in the design, execution, and analysis of the paper, and that they have approved the final version.

\section{REFERENCES}

1. Szelenberger R, Kostka J, Saluk-Bijak J, Miller E. Pharmacological Interventions and Rehabilitation Approach for Enhancing Brain Selfrepair and Stroke Recovery, Home/Current. Neuropharmacology 2020(18);1:51-64.

2. Fonarow GC, Zhao X, Smith EE, et al. Door-to-needle times for tissue plasminogen activator administration and clinical outcomes in acute ischemic stroke before and after a quality improvement initiative. JAMA. 2014;311(16):1632-40.

3. Powers WJ, Rabinstein AA, Ackerson T et al. 2018 Guidelines for the Early Management of Patients With Acute Ischemic Stroke. Stroke 2018;49(3):e46-e99.

4. Schimpf B, Deanda K, Severenuk DA et al. Integration of Real-Time Electronic HealthRecordsand Wireless Technology in a Mobile Stroke Unit. J StrokeCerebrovascDis 2019(28);9:2530-6.

5. Maingard J, Phan K, Lamanna A, et al. Rescue Intracranial Stenting After Failed Mechanical Thrombectomy for Acute Ischemic Stroke:A Systematic Review and Meta-Analysis. World Neurosurg. 2019;132:e235-e245.

6. Saadi A, Mateen FJ. International issues: tele neurology in humanitarian crises. Neurology 2017;89(3):16-9.

7. Sarfo FS, Adamu S, Awuah D, Ovbiagele B. Tele-neurology in sub-Saharan Africa:a systematicreview of theliterature. J NeurolSci 2017;380:196-9.

8. Inan I, Algin A, Sirik M. WhatsApp as an EmergencyTeleradiology Application forCranial CT Assessment in Emergency Services. J Coll Physicians Surg Pak 2020;30(7):730-4.

9. Patel UK, Malik P, DeMasi M, Lunagariya A, Jani VB. Multidisciplinary Approach and Outcomes of Tele-neurology:A Review. Cureus 2019;11(4):4410.

10. Calleja-Castillo JM, Gonzalez-Calderon G. Whatsapp in strokesystems: current use and regulatory concerns. Front Neurol2018;9:388.

11. Ford S, Ajani Z, Chen Q et al. Comparison of Standard Emergency Room Carewith Tele-Stroke Evaluation in Acute Intra cerebral Hemorrhage Management. Stroke 2016;47(1):AWP367.

12. Baratloo A, Rahimpour L, Abushouk Al, Safari S, Lee CW, Abdalvand A Effects of Telestroke on Thrombolysis Times and Outcomes: A Metaanalysis. Prehospital Emergency Care 2018;22(4):472-84. 
13. Barna PM, Hubert GJ, Boy S et al. Telestroke Units Serving as a Model of Care in RuralAreas 10-Year Experience of the Tele Medical Project for Integrative Stroke Care. Stroke2014;45(9):2739-44.

14. Mazighi M, Meseguer E, Labreuche J, et al. TRUST-tPA trial:Telemedicine for remote collaboration with urgentists for stroke-tPA treatment. J Telemed Telecare. 2017;23(1):174-80.

15. Lee VH, Cutting S, Song SY et al. Participation in a TeleStroke Program ImprovesTimeliness of IntravenousThrombolysis Delivery. Telemedicineand e-Health2017;23(1):60-2.

16. Gutowitz S, Legget J, Hart L, Leaman SM, James H, Stillinger T. Theimpact of teleneurologists on acutestrokecare at an advanced primary stroke centre. J Telemed Telecare2020.

17. Bergrath S, Reich A, Rossaint $R$ et al. Feasibility of Prehospital Teleconsultation in AcuteStroke-A Pilot Study in Clinical Routine. PLoSONE. 2012;7(5):36796.

18. Sanchez S, Campos Y,Cadena A et al. Intravenous thrombolysis in theelderly is facilitated by a tele-stroke network:A cross-sectionalstudy. Clin Neurol Nourosurg 2020:197:106177. 